\title{
PEMBELAJARAN KETERAMPILAN BERBAHASA PRODUKTIF BERBASIS COOPERATIVE LEARNING: SEBUAH EKSPERIMEN MODEL PEMBELAJARAN BRAIN DAN INVESTIGASI KELOMPOK
}

\author{
Andri Pitoyo \\ Universitas Nusantara PGRI Kediri \\ e-mail: andripitoyo@unpkediri.ac.id
}

\begin{abstract}
(Tittle: Learning Productive Language Skills Based on Cooperative Learning: An Experiment of Brain Learning Models and Group Investigation). Course learning outcome (CPMK) provides clear direction for the learning process. In addition, it provides a real picture of actions and teaching and learning behavior for university students and lecturers. The learning processes and events that are interesting, fun, innovative, and creative will have a positive effect on the achievement of learning objectives. The statement indirectly requires lecturers to design and implement interesting learning models. The facts show that there are many learning models applied by lecturers that are not in accordance with the specified learning outcomes. The learning achievement of productive language skills (KBP) requires university students to be able to produce scientific papers published in the form of academic seminars. This demand has implications for the teacher's obligation to prepare an interesting, effective, and fun learning model. The purpose of this study was to determine the effect of the BRAIN learning model on Productive Language Skills. This research was conducted at the Nusantara PGRI Kediri University in the odd semester of the 2019/2020 academic year with a sample of 62 students. The group was divided into 2 namely experiment and control. The experimental group used the BRAIN model and the control class used the Group Investigation model. The results showed that there were differences in the average language skills of students between the experimental class and the control class. If viewed from the KBP, the experimental class has an average value of 65.29 which is better than the control class of 63.88 .
\end{abstract}

Keywords: Brain Model, Group Investigation Model, Productive Language Skill

\section{PENDAHULUAN}

Sejak diberlakukannya UndangUndang Nomor 12 Tahun 2012) tentang Pendidikan Tinggi, semua Perguruan Tinggi didorong untuk mampu menyesuaikan diri sesuai dengan aturan yang ada. Di dalam peraturan tersebut Perguruan Tinggi dituntut untuk bisa mengembangkan potensi mahasiswa agar menjadi manusia yang beriman dan bertakwa kepada Tuhan Yang Maha Esa dan berakhlak mulia, sehat, berilmu, cakap, kreatif, mandiri, terampil, kompeten, dan berbudaya untuk kepentingan bangsa (UU Nomor 12 Tahun 2012 Pasal 5a). Oleh karena itu, untuk menghasilkan sejumlah kemampuan tersebut Perguruan Tinggi harus menyelenggarakan proses pembelajaran yang berkualitas. Kualitas pembelajaran yang dimaksud adalah pembelajaran yang memiliki karakteristik interaktif, holistik, integratif, saintifik, kontekstual, tematik, efektif, dan berpusat pada mahasiswa.

Kualitas pendidikan saat ini masih menjadi permasalahan mendasar dalam usaha perbaikan mutu sistem pendidikan nasional. Berbagai upaya telah dilakukan untuk meningkatkan kualitas pendidikan, mencakup semua komponen pendidikan seperti, kurikulum, peningkatan kualitas guru dan dosen, pengadaan buku ajar dan sarana belajar lainnya, pengembangan sistem pembelajaran, penyempurnaan sistem penilaian, penataan organisasi dan manajemen pendidikan (Usman, A. S. (2014). Berbagai masalah lain dalam pelaksanaan pendidikan nasional di antaranya yang menyangkut kebijakan pendidikan, perkembangan anak Indonesia, guru/dosen, relevansi pendidikan, mutu pendidikan, 
pemerataan, manajemen pendidikan dan pembiayaan pendidikan (Suyanta. 2014).

Usaha meningkatkan kualitas dan mutu pendidikan dapat dilakukan dengan kegiatan belajar-mengajar yang baik. Dengan paradigma baru dan perubahan global dunia akhir-akhir ini maka pelaksanaan pembelajaran di perguruan tinggi harus dilakukan dengan pendekatan baru yaitu pembelajaran yang berpusat pada mahasiswa (student centered) (Sidik, D., 2019). Untuk itu berbagai metode pembelajaran yang bernuansa student active learning merupakan metode yang menjadi pilihan dalam melaksanakan PBM. Sesuai ketentuan dalam peraturan pemerintah No 19 Tahun 2005 tentang Standar Nasional Pendidikan maka pelaksanaan pembelajaran di semua jenjang mendidikan diharapkan diselenggarakan secara interaktif, inspiratif, menyenangkan, menantang, memotivasi peserta didik untuk berpartisipasi aktif, serta memberikan ruang yang cukup bagi prakarsa, kreatifitas, dan kemandirian sesuai bakat, minat, dan perkembangan fisik serta psikologis peserta didik.

Program Studi (Prodi) Pendidikan

Bahasa dan Sastra Indonesia sebagai bagian dari sistem Pendidikan Tinggi secara langsung berkomitmen menghasilkan lulusan yang memiliki kompetensi andal baik pada aspek sikap, pengetahuan, maupun keterampilan yang tampak dalam Rencana Pembelajaran Semester (RPS). Rencana pembelajaran yang disusun dosen harus menggambarkan peristiwa belajar yang memberdayakan potensi mahasiswa seara maksimal. Wujud riil dari konteks "memberdayakan" diantaranya pemberian kesempatan yang luas kepada mahasiswa untuk belajar agar mampu menyusun pengetahuan dan pengalaman konkrit. Hal ini sesuai dengan pernyataan bahwa belajar yang memberdayakan si-belajar adalah penyusnan pengetahuan dan pengalaman kongkrit melalui aktivitas kolaboratif, refleksi, dan interpretasi (Nurhayati, I., 2016). Aktivitas tersebut menekankan pentingnya seorang dosen menata lingkungan belajar mahasiswa dengan merencanakan dan menetapkan model pembelajaran yang sesuai. Sejalan dengan konsep tersebut model pembelajaran BRAIN
(Berdayakan, Responsif, Aktualisasikan, Intensifkan, Nikmati) dipandang sebagai model inovatif yang cukup menarik untuk memberdayakan mahasiswa.

Fakta di lapangan menunjukkan keterampilan menulis makalah/karya tulis ilmiah dan kemampuan berbicara dalam bentuk seminar akademik mahasiswa Program Studi PBSI UNP Kediri masih tergolong rendah (di bawah kriteria ketuntasan minimal / 60). Hal ini terbukti ketika dilakukan penilaian terkait dengan pembuatan karya tulis ilmiah terhadap 31 mahasiswa PBSI hasilnya ada 30\% (9 mahasiswa) mendapatkan nilai di atas 75 dan $70 \%$ (22 mahasiswa) mendapatkan nilai antara 45-55. Berdasarkan angket yang dikumpulkan diketahui bahwa rendahnya nilai yang diperoleh mahasiswa tersebut disebabkan oleh beberapa hal, diantaranya (a) motivasi mahasiswa untuk mengikuti perkuliahan rendah, (b) suasanan perkuliahan tidak menarik, dan (c) model pembelajaran yang digunakan monoton. Setelah dilakukan diskusi dengan teman sejawat di Prodi PBSI UNP Kediri diperoleh masukan dan rekomendasi untuk melakukan eksperimen dua model pembelajaran yang berbasis cooperative learning (Brain dan Investigasi Kelompok)

\section{METODE}

Penelitian ini dilakukan di Program Studi Pendidikan Bahasa dan Sastra Indonesia (PBSI) Universitas Nusantara PGRI Kediri (UNP Kediri) pada semester Gasal tahun pelajaran 2019/2020. Metode penelitian yang digunakan dalam penelitian ini adalah metode eksperimen. Sampel penelitian ini secara keseluruhan berjumlah 62 mahasiswa PBSI yang terbagi menjadi kelas eksperimen dan kelas kontrol. Kelas eksperimen merupakan kelas yang proses pembelajarannya dilakukan menggunakan model BRAIN sedangkan kelas kontrol menggunakan model Gorup Investigation. Variabel terikat penelitian ini adalah Keterampilan Berbahasa Produktif (KBP). Pengumpulan data menggunakan tes unjuk kerja (menulis dan berseminar). Uji statistik yang digunakan adalah uji independent sample t-test yang bertujuan membandingkan dua sampel yang tidak saling berpasangan. Hipotesis penelitiannya sebagai berikut. 
H0: Tidak ada perbedaan rata-rata antara kelas eksperimen dan kelas kontrol. Ha: Ada perbedaan rata-rata antara kelas eksperimen dan kelas kontrol.

\section{HASIL DAN PEMBAHASAN}

Model pembelajaran merupakan pola umum perilaku pembelajaran untuk mencapai tujuan pembelajaran. Joyce dan Weil (2009) menyatakan bahwa model pembelajaran adalah suatu rencana atau pola yang dapat digunakan untuk membentuk kurikulum (rencana pembelajaran jangka panjang, merancang bahan pembelajaran, dan membimbing pembelajaran di kelas atau yang lain.

Model pembelajaran Brain merupakan bentuk model pembelajaran inovatif yang berbasis cooperative learning (Trianto, 2010). Brain merupakan akronim dari Berdayakan, Responsif,Aktualisasikan, Intensifkan, Nikmati (BRAIN). Dalam pelaksanaan pembelajaran, model BRAIN yang diterapkan mengacu pada sintaks yaitu (1) Berdayakan; tahap ini mahasiswa diberikan stimulus yang menarik berupa media visual, media audio, media audiovisual, game, atau aktivitas yang bisa membangkitkan motivasi belajar mahasiswa. Tahap ini memberikan peluang yang sangat besar bagi dosen untuk memberdayakan beragam potensi yang dimiliki mahasiswa. Jika belajar diawali oleh kondisi dan suasana mental, emosi, dan suasana hati yang nyaman (fun) maka tujuan pembelajaran akan tercapai dengan mudah. (2) Responsif, tahap ini merupakan tahap merespon semua bentuk stimulus yang muncul di tahap Berdayakan dengan respon bermakna, baik secara individu maupun kelompok (3) Aktualisasikan, merupakan tahap yang menekankan pada proses terbangunnya ide/gagasan cerdas dari mahasiswa. Setiap individu diberikan kesempatan untuk mengemukakan gagasan (komentar, kritik, saran, usul, pertanyaan) terkait dengan materi yang dipelajari, termasuk beragam cara yang paling efektif terkait dengan upaya memahami materi. (4)Intensifkan, tahap kolaborasi antarsiswa dan antarkelompok. Kerjasama yang intensif dalam wujud diskusi memberikan andil terbesar dalam memunculkan beragam karakter positif, diantaranya sikap saling menghargai, menghormati, membantu, perhatian, tanggungjawab, dan saling asah, asih asuh. Kerjasama yang baik dalam memecahkan masalah (khususnya terkait dengan materi perkuliahan) memberikan pelajaran berharga bagi setiap individu untuk meningkatkan pemahaman dan penguasaan materi (5) Nikmati Kesuksesan, merupakan tahap akhir dari peristiwa pembelajaran. Seluruh potensi mahasiswa yang sudah "berdaya" dan mampu mencapai tujuan pembelajaran layak menikmati keberhasilannya. Hal yang bisa dilakukan mahasiswa dalam bentuk pemberian skor/nilai yang tinggi, menyanyi bersama, memunculkan yel-yel menarik.

Sedangkan model pembelajaran Group Investigation menuntutmahasiswa fokus belajar dalam kelompok dan berkoordinasi dengan anggota kelompok lainnya untuk memecahkan masalah. Dalam model pembelajaran ini, mahasiswa diberikan kebebasan untuk memilih sendiri topik dari pembelajaran sehingga tahu gambaran yang akan dipelajari dan cara menjalankan investigasinya (Sangadji, S., 2016). Dalam menerapkan model investigasi kelompok pada pembelajaran diperlukan keterampilan berkomunikasi yang baik antar mahasiswa untuk memperlancar jalannya proses kelompok sehingga sebelum melakukan investigasi kelompok dosen diharapkan memberikanpelatihan-pelatihanberkomunikasi kepada mahasiswa. Keberhasilan pelaksanaan investigasi kelompok sangat bergantung pada kesadaran individu akan tanggungjawabnya terhadap kelompok (Asyari, M, et., al., 2016).

Dalam pelaksanaannya, model investigasi kelompok (group investigation) memiliki enam langkah (fase) pembelajaran (Joyce dan Weil, 2009) dan (Masitoh, S., 2016). Tahap pertama, yaitu: (1) mengidentifikasikan topik dan mengatur mahasiswa ke dalam kelompok (grouping). Pada fase ini mahasiswa meneliti beberapa sumber, mengusulkan sejumlah topik, dan mengkategorikan saransaran. Mahasiswa juga bergabung dengan kelompoknya untuk mempelajari topik yang telah mereka pilih. Komposisi kelompok didasarkan pada ketertarikan mahasiswa dan bersifat heterogen. Dosen membantu dalam pengumpulan informasi dan memfasilitasi 
pengaturan. Tahap keduaadalahmerencanakan tugas yang akan dipelajari (planning). Pada fase ini mahasiswa melakukan perencanaan tentang materi tugas, cara mempelajarinya, peran dan tugas masing-masing mahasiswa, serta tujuan maupun manfaat melakukan investigasi terhadap topik. Tahap ketiga melaksanakan investigasi (investigation). Pada fase ini mahasiswa mengumpulkan informasi, menganalisis data, dan membuat kesimpulan. Tiap anggota kelompok berkontribusi untuk usaha-usaha yang dilakukan kelompoknya. mahasiswa saling bertukar pendapat, berdiskusi, mengklarifikasi, dan mensintesis semua gagasan. Tahap keempat menyiapkan laporan akhir (organizing). Pada fase ini anggota kelompok menentukan pesan-pesan esensial dari tugas yang dikerjakan. Anggota kelompok merencanakan apa yang akan dilaporkan melalui presentasi. Tahap kelima mempresentasikan laporan akhir (presenting). Presentasi dibuat untuk seluruh kelas dalam bentuk seminar. Pendengar (kelompok lain) dilibatkan secara aktif, dan para pendengar melakukan evaluasi berdasarkan kriteria yang telah ditetapkan sebelumnya. Tahap keenam, evaluasi (evaluating). Pada fase ini mahasiswa saling memberikan umpan balik mengenai topik, tugas, dan keaktifan. Dosen dan mahasiswa berkolaborasi untuk mengevaluasi pembelajaran.

Tabel 1. Output Group Statistics

Group Statistics

\begin{tabular}{|c|c|c|c|c|}
\hline Kelompok & $\mathrm{N}$ & Mean & Std. Deviation & Std. Error Mean \\
\hline $\begin{array}{l}\text { Keterampilan_Berbahasa_ } \\
\text { Produktif Eksperimen }\end{array}$ & 31 & 65.2857 & 11.85129 & 1.82869 \\
\hline Kontrol & 31 & 63.8810 & 12.10564 & 1.86794 \\
\hline
\end{tabular}

Berdasarkan Tabel 1, diketahui jumlah data hasil keterampilan berbahasa produktif kelompok eksperimen dan kelas kontrol sebanyak 31 mahasiswa. Nilai rata-rata kelas eksperimen sebesar 65,29 sedangkan kelas kontrol sebesar 63,88. Dengan demikian, secara deskriptif statistik dapat disimpulkan bahwa ada perbedaan rata-rata keterampilan berbahasa produktif mahasiswa antara kelas eksperimen dengan kelas kontrol.

\section{Tabel 2. Output Independent Sample Test}

\begin{tabular}{|c|c|c|c|c|c|c|c|c|c|}
\hline \multicolumn{10}{|c|}{ Independent Samples Test } \\
\hline & $\begin{array}{r}\text { Leve } \\
\text { for Ec } \\
\text { Var }\end{array}$ & $\begin{array}{l}\text { s Test } \\
\text { lity of } \\
\text { aces }\end{array}$ & \multicolumn{7}{|c|}{ t-test for Equality of Means } \\
\hline & \multirow[t]{2}{*}{$\mathrm{F}$} & \multirow[t]{2}{*}{ Sig. } & \multirow[t]{2}{*}{$\mathrm{t}$} & \multirow[t]{2}{*}{$\mathrm{df}$} & \multirow[t]{2}{*}{$\begin{array}{c}\text { Sig. } \\
\text { (2-tailed) }\end{array}$} & \multirow[t]{2}{*}{$\begin{array}{c}\text { Mean } \\
\text { Difference }\end{array}$} & \multirow[t]{2}{*}{$\begin{array}{l}\text { Std. Error } \\
\text { Difference }\end{array}$} & \multicolumn{2}{|c|}{$\begin{array}{c}95 \% \text { Confidence } \\
\text { Interval of the } \\
\text { Difference }\end{array}$} \\
\hline & & & & & & & & Lower & Upper \\
\hline \begin{tabular}{|ll} 
Keterampilan_l & Equal \\
Berbahasa__ & variances \\
Produktif & assumed
\end{tabular} & .011 & .917 & .537 & 82 & .592 & 1.40476 & 2.61406 & -3.79544 & 6.60496 \\
\hline $\begin{array}{l}\text { Equal } \\
\text { variances not } \\
\text { assumed }\end{array}$ & & & .537 & 81.963 & .592 & 1.40476 & 2.61406 & -3.79547 & 6.60500 \\
\hline
\end{tabular}

Berdasarkan tabel 2, diketahui nilai Sig. Levene's Test for Equality of Variances sebesar $0,917>0,05$. Maka dapat diartikan bahwa varians data antara kelompok eksperimen dan kelompok kontrol adalah homogen. Sedangkan juka ditinjau dari hasil output Independent
Samples Test pada bagian Equal Variances Assumed diketahui nilai Sig. sebesar 0,592 $>0,05$. Maka dapat disimpulkan bahwa H0 diterima dan Ha ditolak. Sehingga uji hipotesis menunjukkan bahwa tidak ada perbedaan yang signifikan (nyata) antara keterampilan 
berbahasa produktif kelompok eksperimen dengan kelompok kontrol.

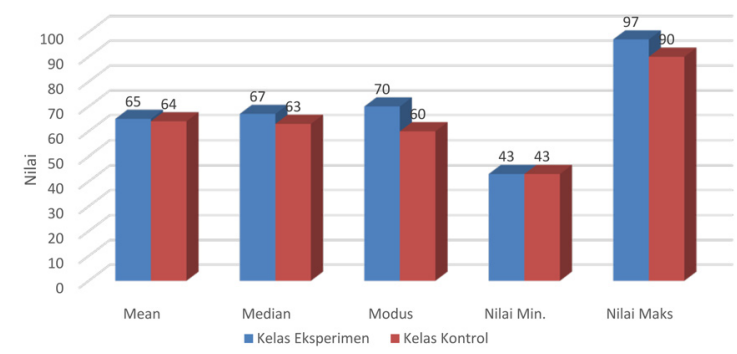

Gambar 1. Nilai Hasil Penelitian Antara Kelas Eksperimen dan Kelas Kontrol

Gambar 1 menunjukkan bahwa pada kelas eksperimen memiliki mean sebesar 65 , median 67 , modus 70 , nilai minimal 43 , dan nilai maksimal 97. Pada kelas kontrol memiliki mean sebesar 64 , median 63 , modus 60 , nilai minimal 43, dan nilai maksimal 90. Hal ini membuktikan bahwa kelas eskperimen yang menerapkan model BRAIN lebih baik daripada kelas kontrol yang menerapkan model Group Investigation (GI). Hal ini membuktikan bahwa Keterampilan Berbahasa Produktif lebih tepat menggunakan model BRAIN daripada model GI.

Terpilihnya model pembelajaran Brain dalam pembelajaran Keterampilan Berbahasa Produktif didasari oleh adanya sejumlah alasan, yaitu dalam Kurikulum Berbasis Standar Nasional Dikti (SNDIKTI) yang mengacu pada Kerangka Kualifikasi Nasional Indonesia (KKNI) dijelaskan bahwa pembelajaran di perguruan tinggi harus bersifat interaktif, holistik, integratif, saintifik, kontekstual, tematik, efektif, kolaboratif, dan berpusat pada mahasiswa. Dengan menerapkan Model Brain (Berdayakan, Responsif, Aktualisasikan, Intensifkan, Nikmati) dalam pembelajaran KBP secara tidak langsung sudah sesuai dengan SNDIKTI. Hal ini bisa dicermati pada karakteristik model ini (sintaknya) sesuai dengan sifat pembelajaran yang diinginkan Dikti. Target akhir dari pembelajaran KBP yang tercermin dalam rumusan CPMK yaitu mahasiswa mampu menyusun makalah bidang bahasa, sastra atau drama dan pembelajaran berdasarkan kaidah karya tulis ilmiah dan mampu mempresentasikannya dengan penuh tanggungjawab dalam bentuk seminar akademik (C6, A4, P2). Tujuan tersebut berimplikasi terhadap tuntutan dosen untuk merencanakan dan melaksanakan pembelajaran yang efektif, tepat sasaran dengan menerapkan model pembelajaran (Nazihah, W., 2020) dan (Ayuningrum, S. (2017).

Model Brain dipilih dalam pelaksanaan PDS (Penugasan Dosen ke Sekolah) Prodi Pendidikan Bahasa dan Sastra Indonesia karena memberikan kontribusi yang sangat berharga terhadap terciptanya suasana pembelajaran mata kuliah KBP. Dengan perkataan lain, penerapan model Brain sangat menunjang terwujudnya capaian pembelajaran mata kuliah KBP. Terkait dengan hakikat komunikasi lisan maupun tulis yang unsur-unsurnya meliputi penulis/pembicara, medium, pesan, pembaca/penyimak, kehadiran Model Brain sangat realistis terciptanya proses produksi bahasa (lisan dan tulis). Keaktifan dimulai dari kegiatan mahasiswa dalam menetapkan topik makalahnya. Topik yang dipilih mahasiswa tentunya dari kegiatan membaca berbagai bentuk karya tulis ilmiah, menyelidiki, observasi, interpretasi secara langsung. Hasil dari aktivitas ini menghasilkan kemampuan mahasiswa dalam membuat desain tulisan yang akan disampaikan secara lisan dalam forum seminar akademik. Bahan pembelajaran yang paling baik adalah memberi banyak latihan komunikasi (tulis dan lisan) yang bermakna sehingga dapat mendorong mahasiswa mengembangkan kemahiran berbahasa produktifnya. Pengalaman belajar yang baik adalah memberi kesempatan kepada mahasiswa untuk mengambil bagian dalam peristiwa berbahasa yang bermakna. Sumber belajar yang tepat adalah sumber belajar yang memberikan pengalaman lansung bagi mahasiswa untuk belajar berbahasa produktif, baik secara lisan maupun tulis (Aji, H. A. P., 2020). Oleh karena itu, model pembelajaran Brain dipandang sesuai dengan tujuan-tujuan tersebut.

Penerapan model pembelajaran Brain dalam KBP terwujud dalam perencanaan, pelaksanaan, evaluasi, dan tindak lanjut. Pernyataan ini sangat logis mengingat proses 
pembelajaran KBP harus direncanakan, dilaksanakan, dievaluasi dan ditindaklanjuti. Pelaksanaan model Brain sangat dipengaruhi oleh empat aspek tersebut. Oleh karena itu, apabila dalam pembelajaran KBPmenggunakan model Brain, harus mewarnai keempat aspek tersebut secara baik. Aspek tersebut dijelaskan sebagai berikut.

Pertama, wujud penerapan model brain dalam aspek perencanaan. Perencanaan pembelajaran model Brain disusun secara sistematis dalam Rencana Pelaksanaan Pembelajaran (RPP) yang bersumber dari Rencana Pembelajaran Semester (RPS). RPP yang disusun meliputi penuangan Capaian Pembelaran Mata Kuliah (CPMK), Kompetensi Akhir yang Direncanakan (KAD), Indikator, Tujuan Pembelajaran, Materi, Kegiatan Pembelajaran,Media, SumberBelajar,Evaluasi, dan Referensi. Komponen-komponen inilah yang diwarnai oleh model Brain, terutama pada komponen kegiatan pembelajaran. Hal ini dikarenakan fokus model pembelajaran adalah aspek kegiatan/sintak/tahapan/aktivitas yang dilakukan oleh mahasiswa dan dosen (Wicaksono, G. W., 2018).

Kedua, wujud penerapan model brain dalam aspek pelaksanaan. Pelaksanaan pembelajaran mata kuliah KBP merupakan aktualisasi rencana pembelajaran KBP yang telah disusun. Dalam pelaksanaan pembelajaran tampak semua komponen yang sudah direncanakan akan berinteraksi secara maksimal, untuk mewujudkan model Brain diperlukan pendekatan, strategi, metode, dan teknik yang sesuai. Pendekatan pembelajaran KBP yang muncul adalah Pendekatan Komunikatif, Pendekatan Keterampilan Proses, dan Pendekatan Saintifik. Pendekatan Komunikatif terwujud secara maksimal pada aktivitas mahasiswa saat berdiskusi memecahkan persoalan terkait dengan penyusunan topik, kerangka makalah dan penyususnan makalah (Kurniawan, K., 2016). Mahasiswa secara interaktif menyampaikan gagasannya secara sungguh-sungguh dan menyenangkan dalam kelompok kecil maupun besar (kelas). Pendekatan Keterampilan Proses terwujud sejak kegiatan pendahuluan, inti, sampai pada evaluasi. Pendekatan saintifik juga tampak pada saat mahasiswa observasi, saling mengemukakan pertanyaan, mengumpulkan informasi (data), mengasosiasi, dan mengomunikasikan gagasannya (Machin, A., 2014).

Ketiga, wujud penerapan model brain dalam aspek evaluasi. Perwujuan model Brain dalam evaluasi ditekankan pada bagaimana mahasiswa menemukan sesuatu baik secara mandiri maupun kelompok, dan mengolah hasil temuannya, serta pengalaman menemukan sesuatu dalam konteks nyata. Dengan demikian, butir-butir evaluasi yang dibuat tidak sekadar berisi hasil atau temuan belajar KBP, tetapi juga meliputi proses menemukan temuan/ hasil belajar, serta bagaimana mengolah hasil temuan tersebut.

Keempat, Wujud Penerapan Model Brain dalam Aspek Tindak lanjut. Setelah dilakukan evaluasi, pembelajaran KBP perlu dilakukan tindak lanjut. Hasil evaluasi merupakan salah satu bahan pertimbangan untuk menentukan bentuk dan isi tindak lanjut pembelajaran. Berdasarkan fakta di lapangan, Model Brain mampu meningkatkan keterampilan menulis ilmiah mahasiswa. Sejumlahkeunggulandiantaranya(a)mahasiswa mampu mengembangkan pengalaman, mengerjakan sesuatu, merespon sesuatu, dan menjalankan sesuatu dengan kerjasama secara baik, (b) antarmahasiswa memiliki kepedulian, perhatian, dan penghargaan terhadap beragam pendapat, dan (c) memiliki rasa kebergantungan positif dalam proses pembelajaran. Tindak lanjut dari fakta ini adalah (a) proses belajar mahasiswa sebaiknya direncanakan secara maksimal, dengan menekankan pada kegiatan yang melibatkan beragam pengalaman dengan konteks yang menarik, (b) proses belajar dikelola dengan bijaksana, yaitu adanya bimbingan dan stimulan (bukan didominasi dengan paksaan), dan (c) proses belajar akan berjalan secara baik jika dikembangkan dalam lingkungan yang kaya gagasan.

\section{SIMPULAN}

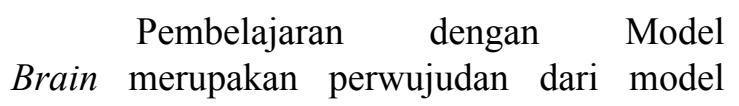


pembelajaran cooperative yang mewadahi bagaimana mahasiswa dapat bekerja secara baik dalam kelompok untuk tujuan bersama. Situasi kooperatif yang dilalui mahasiswa dalam bentuk saling membantu, menghargai, dan berkompetisi secara sehat merupakan upaya untuk mencapai tujuan bersama. Pelaksanaan model Brain secara maksimal akan memberikan kontribusi positif, yaitu (a) meningkatkan prestasi belajar mahasiswa, hubungan sosial, menumbuhkan sikap toleransi, dan menghargai pendapat orang lain, (b) meningkatkan dan mengembangkan kemampuan berpikir kritis serta memudahkan dalam memecahkan masalah. Pada penelitian ini, model Brain diterapkan pada kelas eksperimen sedangkan pada kelas kontrol menggunakan model Group Investigation. Hasil penelitian menunjukkan bahwa ada perbedaan rata-rata keterampilan berbahasa produktif mahasiswa antara kelas eksperimen dengan kelas kontrol. Perbedaan tersebut bisa dilihat dari nilai rerata kelas eksperimen sebesar 65,29 sedangkan kelas kontrol sebesar 63,88 . Jika diamati, perbedaan tersebut secara signifikan tidak menunjukkan perbedaan yang besar. Hal tersebut dikarenakan kedua model pembelajaran sama-sama menerapkan konsep pembelajaran berbasis kelompok. Perbedaan terlihat pada model Brain yang menerapkan stimulus yang lebih menarik berupa media visual, media audio, media audiovisual, game, atau aktivitas yang bisa membangkitkan motivasi belajar mahasiswa (Yusantika, F. D., et., all., 2018).

\section{DAFTAR PUSTAKA}

Aji, H. A. P. (2020). Membuat Siswa Lebih Produktif dalam Berbahasa Accountable Talk. Jurnal Al-Azhar Indonesia Seri Humaniora, 5(3), 168174.

Asyari, M., Al Muhdhar, M. H. I., \& Susilo, H. (2016). Improving Critical Thinking Skills Through The Integration of Problem Based Learning and Group Investigation. International Journal for Lesson and Learning Studies.
Ayuningrum, S. (2017). Peningkatan Hasil Belajar Bahasa Indonesia pada Aspek Keterampilan Berbahasa melalui Model Pembelajaran Kreatif Produktif di SMK Islam PB. Soedirman 1. Visipena Journal, 8(2), 351-372.

Joyce, B. Dan Weil, M. 2009. Models of Teaching. New Jersey: Prentice-Hall, Inc.

Kurniawan, K. (2016). Strategi Pembelajaran Bahasa Indonesia Berdasarkan Pendekatan Komunikatif. Jurnal Ilmu Pendidikan, 9(4).

Machin, A. (2014). Implementasi Pendekatan Saintifik, Penanaman Karakter dan Konservasi pada Pembelajaran Materi Pertumbuhan. Jurnal Pendidikan IPA Indonesia, 3(1).

Masitoh, S. (2016). Peningkatan Aktivitas Belajar dengan Pembelajaran Investigasi Kelompok dalam Kuliah Metode Penelitian PLB II. Jurnal Ilmu Pendidikan, 13(2).

Nazihah, W. (2020). Relevansi Faktor Psikolinguistik dengan Keterampilan Berbicara pada Pembelajaran Keterampilan Berbahasa

Produktif. Logat: Jurnal Bahasa Indonesia dan Pembelajaran, 7(1), 67-84.

Nurhayati, I. (2016). Implikasi Budaya Sekolah terhadap Perikehidupan Akademis. Edukasia: Jurnal Penelitian Pendidikan Islam, 11(1).

Peraturan Pemerintah Republik Indonesia Nomor 19 Tahun 2005 tentang Standar Nasional Pendidikan.

Sangadji, S. (2016). Implementation of Cooperative Learning with Group Investigation Model to Improve learning Achievement of Vocational School Students in Indonesia. International Journal of Learning \& Development, 6(1), 91103.

Sidik, D. (2019). Pendidikan Era 21 dan Adopsi Model Pembelajaran (Kajian pada Pembelajaran Pendidikan Teknik Elektronika). Jurnal MEKOM 
(Media Komunikasi Pendidikan Kejuruan), 6(2).

Suyanta. (2014). Paradigma Baru dalam Pembelajaran di Perguruan Tinggi. Yogyakarta: FMIPA Universitas Negeri Yogyakarta.

Trianto.(2010).MendesainModelPembelajaran Inovatif - Progresif. Jakarta: Kencana. Undang-Undang Republik Indonesia Nomor 12 Tahun 2012 tentang Pendidikan Tinggi.

Usman, A. S. (2014). Meningkatan Mutu Pendidikan melalui Penerapan Manajemen Berbasis Sekolah. Jurnal Ilmiah Didaktika: Media Ilmiah Pendidikan dan Pengajaran, 15(1), 1331.
Wicaksono, G. W. (2018). Lective: Desain Perangkat Pembelajaran Online. In Prosiding SENTRA (Seminar Teknologi dan Rekayasa) (No. 1).

Yusantika, F. D., Suyitno, I., \& Furaidah, F. (2018). Pengaruh Media Audio dan Audio Visual terhadap Kemampuan Menyimak Siswa Kelas IV. Jurnal Pendidikan: Teori, Penelitian, dan Pengembangan, 3(2), 251-258. 